\title{
Long-term behavior of cracked fiber reinforced concrete under service conditions
}

\author{
D.H. Monetti ${ }^{\text {, }}$, A. Llano-Torre ${ }^{\mathrm{b}}$, M.C. Torrijos ${ }^{\mathrm{a}}$, G. Giaccio ${ }^{\mathrm{a}}$, R. Zerbino ${ }^{\mathrm{a}}$, J.R. Martí-Vargas ${ }^{\mathrm{b}, *}$, P. Serna ${ }^{\mathrm{b}}$ \\ ${ }^{a}$ LEMIT-CIC and Faculty of Engineering UNLP, La Plata, Argentina \\ ${ }^{\mathrm{b}}$ ICITECH, Institute of Concrete Science and Technology, Universitat Politècnica de València, Valencia, Spain
}

\section{H I G H L I G H T S}

- Creep behavior of cracked fiber reinforced concrete is analyzed in service conditions.

- Different stress levels and pre-cracking damages are considered.

- Creep does not generate negative effects on the residual post-creep behavior.

- Crack Opening Rate depends on both pre-cracking damage and applied stress level.

- An expression to predict Crack Opening Rate values is proposed.

\section{A R T I C L E I N F O}

\section{Article history:}

Received 26 July 2018

Received in revised form 28 October 2018

Accepted 30 October 2018

\section{Keywords:}

Creep

Fiber-reinforced concrete

Steel fiber

Bending

Crack opening

\begin{abstract}
A B S T R A C T
This paper presents an experimental study on creep behavior of cracked Fiber Reinforced Concrete (FRC). To this end, a conventional strength concrete incorporating hooked-end steel fibers was used. In order to represent service conditions, specimens under low sustained loads with small pre-cracking damage (lower than $0.5 \mathrm{~mm}$ ) were tested and analyzed. Taking as a reference the residual stress $f_{\mathrm{R}, 1}$ determined according to EN 14651:2007, different stress levels for the creep tests were applied: $25 \%, 35 \%$ and $45 \%$ of $f_{\mathrm{R}, 1}$. For the pre-cracking damage, several initial crack openings were considered: $0.05,0.1,0.2,0.3$ and $0.5 \mathrm{~mm}$. The specimens were tested under a four-point bending scheme for 180 days in controlled environmental conditions. The Crack Opening Rate (COR) was used as parameter to characterize the creep behavior of cracked FRC. After the creep tests, conventional flexural tests were carried out to evaluate the residual capacity and to survey the fiber density of each specimen. Both the stress level and the initial crack opening factors affected significantly the creep behavior. In all cases, the measured increases in crack openings resulted compatible with service conditions, and no negative effects on the residual post-creep behavior were observed. An expression to predict Crack Opening Rate values is proposed.
\end{abstract}

(c) 2018 Elsevier Ltd. All rights reserved.

\section{Introduction}

Fiber Reinforced Concrete (FRC) is an enhanced composite material obtained by adding fibers into concrete. Different types of fibers can be used with the aim of improving the postcracking concrete performance for a variety of structural applications. A main contribution played by fibers consists in controlling cracks propagation, which lead to improvements in tensile and

* Corresponding author at: ICITECH, Universitat Politècnica de València, Building $4 \mathrm{~N}$, Camino de Vera s/n, 46022 Valencia, Spain.

E-mail addresses: dmonetti@ing.unlp.edu.ar (D.H. Monetti), aillator@upv.es (A. Llano-Torre), mc.torrijos@conicet.gov.ar (M.C. Torrijos), ggiaccio@ing.unlp.edu. ar (G. Giaccio), zerbino@ing.unlp.edu.ar (R. Zerbino), jrmarti@cst.upv.es (J.R. Martí-Vargas), pserna@cst.upv.es (P. Serna). impact toughness, ductility and durability [1]. This contribution is activated from fiber pull-out after concrete cracking due to the fiber bridging mechanisms across the concrete crack surfaces $[2,3]$. Once the action of the fibers has begun, the stabilization of cracks to prevent excessive crack openings through time constitutes a crucial issue regarding the service life of FRC structures $[2,4]$. In fact, the crack width of FRC beams seems to stabilize after 10 months under sustained load [5], which is not well predicted from codes [6]. Therefore, the post-cracking behavior due to the time-dependent fiber pull-out may be one of the significant sources of time-dependent deformation under sustained loads (creep in the following), along with the development of new cracks [7], which will constitute a complex phenomenon as properties of the concrete matrix change due to aging and the mechanical behavior is dependent on the duration of loading [8]. 


\section{Nomenclature}

\section{CMOD Crack Mouth Opening Displacement}

$\mathrm{CMOD}_{\mathrm{p}}$ maximum CMOD reached in the pre-cracking process

$\mathrm{CMOD}_{\mathrm{pr}}$ residual CMOD after the pre-cracking process

$\mathrm{CMOD}_{\mathrm{ci}}$ instantaneous CMOD at loading in the creep period

$\mathrm{CMOD}_{\mathrm{cd}}^{\mathrm{j}}$ deferred CMOD after $\mathrm{j}$ days under sustained load in the creep period

$\mathrm{CMOD}_{\mathrm{ct}}^{\mathrm{j}}$ total CMOD after $\mathrm{j}$ days in the creep period $\left(\mathrm{CMOD}_{\mathrm{ci}}+\right.$ CMOD $_{\text {cd }}^{\mathrm{j}}$ )

CMOD $_{\text {cri }}$ instantaneous CMOD recovery after unloading

$\mathrm{CMOD}_{\mathrm{crd}}$ deferred CMOD recovery after unloading

$\mathrm{CMOD}_{\mathrm{o}}^{\mathrm{j}}$ absolut CMOD after $\mathrm{j}$ days, referred to origin of deformations

$\mathrm{COR}^{\mathrm{j}-\mathrm{k}} \quad$ Crack Opening Rate between $\mathrm{j}$ and $\mathrm{k}$ days

$\mathrm{COR}_{\text {th }} \quad$ theoretical Crack Opening Rate

CTOD Crack Tip Opening Displacement

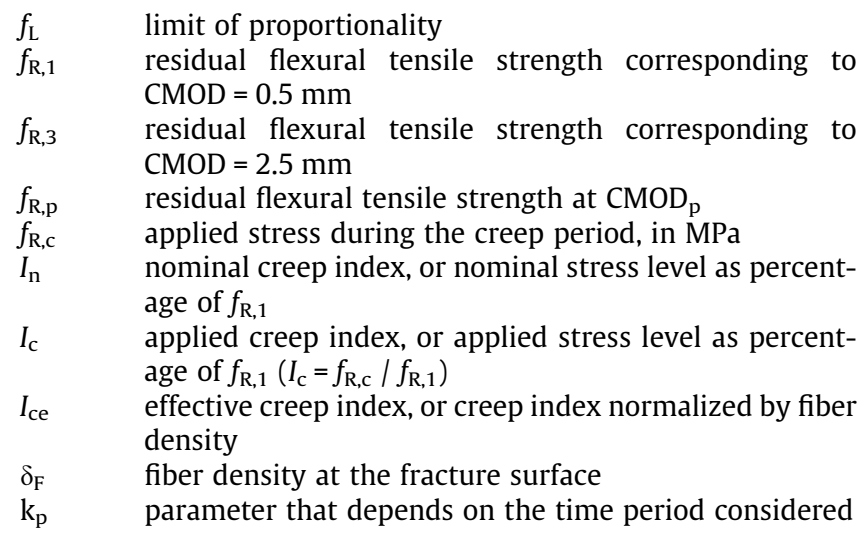

With the increased knowledge and progress in new design perspectives $[3,9,10]$, the improved properties of FRC over conventional reinforced concrete with standard rebars are allowing an increased use. However, a proper knowledge on the long-term behavior of FRC has not yet been achieved as research and literature on this topic are still scarce $[1,11,12]$.

In 2000 both ASTM and RILEM organizations offered test methods to determine the residual-behavior of FRC: the first version of ASTM C1399 [13], the early recommendations proposed by RILEM TC162TDF [14] and the actual European Standard 14651:2005 + A1:2007 [15], which has been adopted by several countries. This allowed a better characterization of the ability of the fibers to provide crack bridging forces, that is, the post-cracking behavior of FRC. However, these standards only allow gaining a better understanding of the instantaneous behavior of FRC. Regarding the long-term behavior of FRC, different phenomena may contribute in the cracked state: creep of the concrete matrix, creep of the fibers material and timedependent fiber slip by a pull-out process at the fiber/matrix interface; the extent to which each of these phenomena contributes to the global behavior (and to creep failure) is not yet clear [12].

In the absence of a standard test, the experimental methodology commonly applied in beams by researchers considers some aspects included in EN 14651 [15], mainly those focused on the specimen characteristics. Also, variations in load scheme (threepoint bending tests (3PBT) or four-point bending tests (4PBT)), pre-cracking process, and load level and time period, among others factors, has been carried out. Concerning experimental research on flexural creep behavior, the literature found in international journals reports important contributions from research on steel FRC (SFRC) $[2,4,16-20]$.

Some studies were carried out introducing large initial crack widths $(0.5-2 \mathrm{~mm}$ in beams $[2,16,18-20]$, and $3.5 \mathrm{~mm}$ in round panels [4]), and also high sustained load levels were applied in relation to cracking load (more than $90 \%$ in some cases [2], commonly about $50-70 \%$ [16,19], and lower than $50 \%$ in few cases [20].

Stable responses without increased crack width were obtained in [2] for the following cases: (a) for a small Crack Mouth Opening Displacement (CMOD) of $0.2 \mathrm{~mm}$ regardless the stress level; and (b) for a CMOD of $0.5 \mathrm{~mm}$ when stress level ratio was under the $80 \%$ of the residual stress reached during the initial cracking process. By using multiple linear regression analysis to relate measured creep parameters to fiber geometry and content, concrete strength and composition and high sustained load level - ranging from $50 \%$ to $90 \%$ of the residual flexural tensile strength corresponding to a pre-crack of $0.5 \mathrm{~mm}$ CMOD-, it was found that fiber content and fiber slenderness together with load ratio were the main factors influencing flexural creep behavior [16]. In addition to higher creep coefficients for greater initial crack openings, creep performance was found influenced by the fiber distribution [17]. From comparative studies, flexural creep behavior was found influenced by both the fiber type and the load level [4], in this case by using round panels made of shotcrete which were pre-cracked up to $3.5 \mathrm{~mm}$. It was stated that the fiber type and environmental conditions can affect creep behavior and the residual response of SFRC [18]. Similar creep behavior was observed by using three- and four-point loading configurations [19].

With regard to the load level, it was found that $50 \%$ guarantees a durable system with a long-term load carrying capacity in the cracked state when macro-synthetic fibers are used [21]. Also, it was detailed that for load levels below $50 \%$, the measured flexural creep coefficients were similar to those of the unreinforced concrete loaded in compression [21]. The tensile creep of cracked SFRC also increases as the stress level increases [22]. Recently, in a comparative study including steel fibers and synthetic fibers which considered initial crack widths ranging from 0.2 to $2 \mathrm{~mm}$ and applied sustained stress level of $0.45 f_{\mathrm{R}, 1}$ for the creep test [20], it was concluded that for SFRC the Crack Opening Rate (COR) shows stabilized values after 30 days of creep tests regardless the initial CMOD. Also, it was found in [20] that COR values for synthetic macro-fibers after 180 days of creep test show more variability than those for steel fibers, and that stress level seems to be more significant than initial crack opening for COR values. For this reason, it was recommended in [20] to study the influence of initial CMOD in creep test with different stress levels. At this point, it is important to highlight that velocity stabilization means small continuous deferred deformations but not deferred deformations stop.

Therefore, this paper focuses on the study of the long-term behavior of cracked steel FRC specimens in suitable service conditions for structural elements. The significance of the initial crack width and the load levels as the main variables affecting the long-term performance are analyzed with the aim of defining load levels safe enough to keep service conditions along the life of the structure.

\section{Experimental program}

\subsection{Materials}

Two different batches ("a" and "b") with the same FRC matrix were cast. The concrete mix design shown in Table 1 was adopted 
since it is a usual concrete in FRC structures. Hooked-end steel fibers $50-\mathrm{mm}$ long and $1-\mathrm{mm}$ diameter were used with a dosage of $50 \mathrm{~kg} / \mathrm{m}^{3}$. It was expected to obtain a residual performance classified "c" by the fib Model Code [23], what means a ratio $f_{R, 3} / f_{R, 1}$ between 0.9 and 1.1 .

\subsection{Specimens}

The experimental program was developed to study the influence of the damage level (initial crack opening) and the stress level on the flexural creep behavior of cracked FRC. A total of 18 prismatic specimens of $150 \times 150 \times 600 \mathrm{~mm}$ were cast. In addition, three $\varnothing 150 \times 300 \mathrm{~mm}$ cylindrical specimens were cast for each batch in order to perform characterization tests in compression. All specimens were demolded and cured for 28 days in moist chamber $\left(20 \pm 3{ }^{\circ} \mathrm{C}\right.$, relative humidity $\left.95 \%\right)$. The average concrete compressive strength at 28 days was 41.7 and $39.2 \mathrm{MPa}$ for batches "a" and "b", respectively.

All prismatic specimens were prepared as proposed in EN 14,651 [15], with a $25 \mathrm{~mm}$ depth notch sawed at midspan. At 28 days, two specimens (one from each batch) were tested for characterization according to EN 14,651 [15] until a CMOD of $3.5 \mathrm{~mm}$, and the others were used for creep tests. The CMOD was controlled by means of a clip gauge placed at both sides of the notch. The stress at the Limit Of Proportionality (LOP, $f_{\mathrm{L}}$ ) and the residual strengths at CMOD of 0.5 and $2.5 \mathrm{~mm}\left(f_{\mathrm{R}, 1}\right.$ and $\left.f_{\mathrm{R}, 3}\right)$ were obtained.

\subsection{Testing details}

Based on an experimental test method to characterize flexural creep behavior of pre-cracked FRC specimens [9], which has been used in recent studies [24,25], the complete flexural creep test consisted of three main stages (Fig. 1): "pre-cracking”, "creep period" and "rupture after creep (or post-creep)". In the first stage, specimens were pre-cracked using a 3PBT configuration as proposed in EN 14,651 [15] up to the desired $\mathrm{CMOD}_{\mathrm{p}}$ (point B in Fig. 1, after point A -limit of proportionality- is reached) and then unloaded (point $\mathrm{C}$ ). In the second stage, the cracked specimens are located into the creep frames and loaded (from point $D$ to $E / E^{\prime} / E^{\prime \prime}$ ) in a 4PBT configuration. The load, that was kept constant over time (creep period, from point E to F, or E' to F'; or E" to F"), was selected in order to reach a stress in the cracked section as close as possible to the nominal creep index $I_{n}$, which was established as a percentage of the residual flexural strength at a CMOD of $0.5 \mathrm{~mm}\left(f_{\mathrm{R}, 1}\right)$. During the creep period, the crack opening evolution was registered. Once the creep period was finished, the specimens were unloaded (from points $F / F^{\prime} / F^{\prime \prime}$ to $G$ ), and afterwards were tested again in bending until failure (points $\mathrm{H}$, I and J). Applied stresses were computed from forces considering a linear distribution along the cross section of specimens according to EN 14651:2007 [15] and taking into account the actual loading configuration (4PBT in the creep period and 3PBT in pre-cracking and post-creep periods).

The creep behavior was analyzed in specimens having different initial damage level $\left(\mathrm{CMOD}_{\mathrm{p}}\right)$, all of them with suitable values com-

Table 1

Mix design of the FRC.

\begin{tabular}{ll}
\hline Component & Content $\left(\mathrm{kg} / \mathrm{m}^{3}\right)$ \\
\hline Portland Cement (type CPF40) & 410 \\
Water & 170 \\
Natural siliceous sand & 935 \\
Granitic crushed stone (12 mm maximum size) & 825 \\
Superplasticizer & 3.4 \\
Steel fibers & 50
\end{tabular}

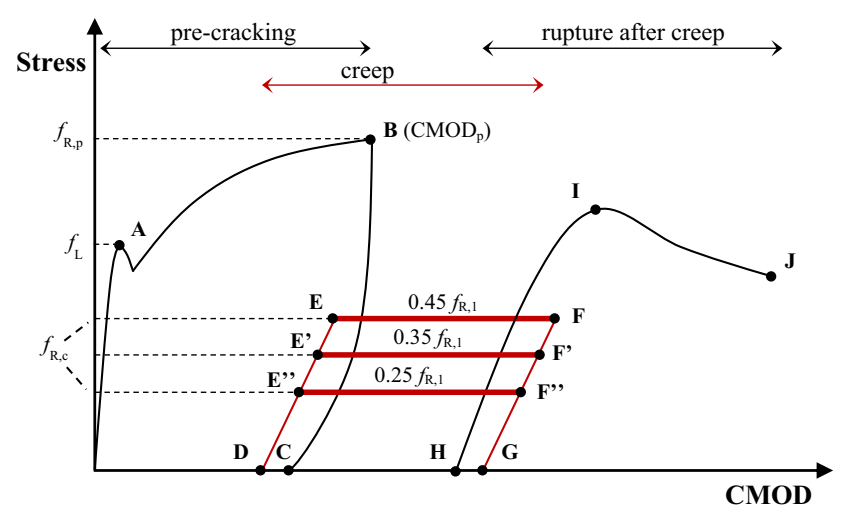

Fig. 1. Main stages of the cracked FRC creep test methodology.

patible with service conditions. The selected $\mathrm{CMOD}_{\mathrm{p}}$ were $0.05,0.1$, $0.2,0.3$ and $0.5 \mathrm{~mm}$. Regarding the sustained load, low stress levels were applied to specimens: $25 \%, 35 \%$ and $45 \%$ of $f_{\mathrm{R}, 1}$.

As the pre-cracking stage ended in most specimens before a $0.5 \mathrm{~mm}$ crack width, it was not possible to refer the applied stress to the specific $f_{\mathrm{R}, 1}$ of each specimen. Therefore, it was adopted as a general reference the average of $f_{\mathrm{R}, 1}$ values obtained from the three specimens pre-cracked up to $0.5 \mathrm{~mm}$ and the two specimens that were tested up to $3.5 \mathrm{~mm}$ used for FRC characterization.

The creep specimens were identified based on the nominal $\mathrm{CMOD}_{\mathrm{p}}$ achieved in the pre-cracking stage $(0.05,0.1,0.2,0.3$ and $0.5 \mathrm{~mm}$ ) followed by the letter of the FRC batch ("a" or "b") and the stress level $\left(25,35\right.$ or 45 , as \% of $\left.f_{\mathrm{R}, 1}\right)$ applied during the creep period. By way of example, $0.3 \mathrm{~b}-35$ corresponds to a specimen from concrete bath "b", with a pre-crack $0.3 \mathrm{~mm}$ width, loaded at $0.35 f_{\mathrm{R}, 1}$ during the creep period.

After curing in the moist chamber for 28 days, the prismatic specimens remained in the laboratory environment $\left(20^{\circ} \mathrm{C}\right.$, relative humidity $70 \%$ ) during an additional time span of one month. Precracking tests in bending were performed during the first two weeks after curing. Once the desired pre-crack level was reached, the stress corresponding to the $\mathrm{CMOD}_{\mathrm{p}}$ was recorded and was identified as $f_{\mathrm{R}, \mathrm{p}}$, and then the specimens were unloaded and the residual pre-crack value $\left(\mathrm{CMOD}_{\mathrm{pr}}\right)$ was recorded. After unloading, the cracked specimens were turned $90^{\circ}$ and placed on plywood boards in order to avoid any influence on the crack opening during transport or waiting times. Then, with the aim of reducing thermal and drying shrinkage effects during creep measurements, the specimens were stored in the creep test room where the temperature was kept constant at $22 \pm 3{ }^{\circ} \mathrm{C}$.

After one week, the specimens were placed in the frames and the sustained creep loads were applied. The applied stress during the creep period was identified as $f_{\mathrm{R}, \mathrm{c}}$. Using a 4PBT configuration, a multiple specimen's setup in column was adopted for the creep period. Fig. 2 shows the load configuration inside the creep frame as well as details of the dial gauges used for the measurements of crack evolution. The specimens with highest residual strength were placed at the bottom of the column in order to minimize differences in stress levels due to weight of the upper specimens, in this way, the applied stresses were similar.

The CMOD values for each specimen were registered during 180 days by means of a dial gauge placed at one side of the specimen. Additionally, with the aim of improving the accuracy of instantaneous deformations during the loading as well as to record the creep variations during the first days, one Linear Variable Differential Transformer (LVDT) was located at one side of each specimen measuring the Crack Tip Opening Displacement (CTOD) as seen in Fig. 2. Since the notch depth was $25 \mathrm{~mm}$, the CTOD were 

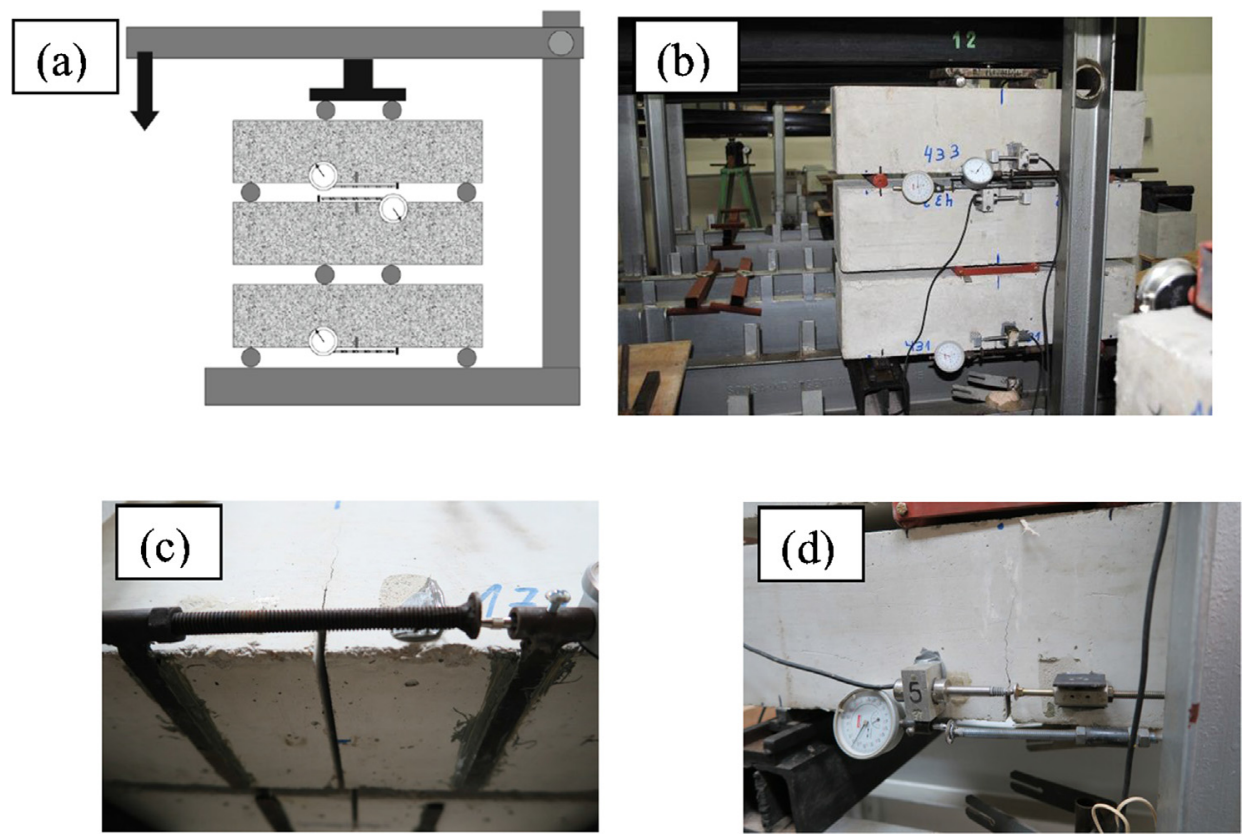

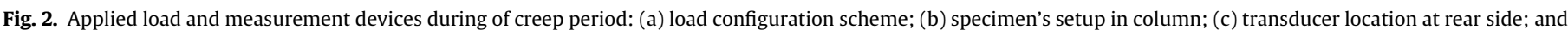
(d) transducer location at front side.

corrected by applying a factor of 1.2 to compare with those of the CMOD. This correction factor was obtained as the ratio of the distance of both transducers referred to the top of the specimen $(150 / 125=1.2)$.

Based on the creep test results, the Crack Opening Rate (COR) was calculated to explore the conditions for crack stability. This parameter evaluates the deferred crack opening rate in a certain period of time by means of Eq. (1):

$\mathrm{COR}^{\mathrm{j}-\mathrm{k}}=\left(\mathrm{CMOD}_{\mathrm{ct}}^{\mathrm{k}}-\mathrm{CMOD}_{\mathrm{ct}}^{\mathrm{j}}\right) /(\mathrm{k}-\mathrm{j})$

where $\mathrm{j}$ and $\mathrm{k}$ are the age in days after loading (within the creep period), and $\mathrm{CMOD}_{\mathrm{ct}}^{\mathrm{j}}$ and $\mathrm{CMOD}_{\mathrm{ct}}^{\mathrm{k}}$ are the total crack openings at $j$ and $k$ times in the creep period, respectively.

After 180 days under sustained loads (creep period), the specimens were unloaded and kept in the frames while the CMOD recovery was measured during 30 days. Afterward, the specimens were removed from the creep frames, and then tested until failure using a 3PBT configuration following the general guidelines of EN 14651 standard. Finally, the number of fibers at the fracture surface was counted and the density of fibers $\left(\delta_{\mathrm{F}}\right)$ was calculated.

\section{Test results}

\subsection{Characterization and pre-cracking tests results}

Fig. 3 shows the curves of the flexural tests for each specimen in pre-cracking stage (cases (a)-(e)) as well as the complete tests performed on two prismatic specimens in accordance to EN 14,651 (case (f)). Table 2 summarizes the obtained results for both characterization and pre-cracking tests. In case of the specimens where the pre-cracking stage ended before $0.5 \mathrm{~mm}$ for CMOD, the stress corresponding to $\mathrm{CMOD}_{\mathrm{p}}\left(f_{\mathrm{R}, \mathrm{p}}\right)$ is detailed instead of $f_{\mathrm{R}, 1}$.

As shown in Table 2, the average $f_{\mathrm{R}, 1}$ obtained from the two specimens used for characterization test and the three specimens pre-cracked up to $0.5 \mathrm{~mm}$ was $5.39 \mathrm{MPa}$. This average residual strength was the reference stress value that served to obtain the sustained load to be applied for each specimen in the creep period stage.

\subsection{Distribution of specimens in the frames}

The specimens (with different $\mathrm{CMOD}_{\mathrm{p}}$ ) were located in six frames according to the nominal stress levels: 5 specimens at 0.25 of reference $f_{\mathrm{R}, 1}(1.35 \mathrm{MPa}), 5$ specimens at 0.35 of reference $f_{\mathrm{R}, 1}(1.89 \mathrm{MPa})$ and 6 specimens at 0.45 of reference $f_{\mathrm{R}, 1}$ (2.43 MPa). Table 3 shows the distribution and the relative position for each specimen inside the corresponding creep frame: top, middle or bottom. The indicated load corresponded to that applied on the top specimen of the column; in the case of middle and bottom specimens, the weight of the upper specimens was considered to obtain the applied stress (presented in Table 4). As a result, the applied stresses $\left(f_{\mathrm{R}, \mathrm{C}}\right)$ for each stress level group ranged from 1.30 to $1.38 \mathrm{MPa}$ (24.1 to $25.6 \%$ ), from 1.82 to $1.95 \mathrm{MPa}$ (33.7 to $36.1 \%$ ), and from 2.27 to $2.54 \mathrm{MPa}$ (42.0 to $47.0 \%$ ) respectively, and were not exactly the desired stress level values in all cases.

The creep period stage was developed in a room with controlled temperature $\left(22 \pm 3{ }^{\circ} \mathrm{C}\right)$. Fig. 4 shows the logs of temperature and relative humidity inside the room during the 6 months under sustained load and one additional month where the $\mathrm{CMOD}_{\text {crd }}$ measurements were continued while the specimens remained unloaded. The experiences started in winter and, as it can be seen, during the first months the relative humidity was near $50 \%$, whereas at later ages the humidity increased up to $80 \%$.

\subsection{Measurement corrections due to shrinkage}

As the CMOD was determined by dial gauges (see Fig. 2), the measures were referred to two points located on both sides of the crack with a base length close to $150 \mathrm{~mm}$; in certain cases, as multiple specimens arrangement was used, it was necessary to increase the base length in order to place the dial gauges. Due to the low humidity in the creep room, it was expected that concrete undergo drying shrinkage. Therefore, the dial measurements included both the creep crack opening increase and the length reduction due to concrete shrinkage. It must be noted that many studies in the literature were performed using high stress levels and wider initial cracks, and the former effect is preeminent. 


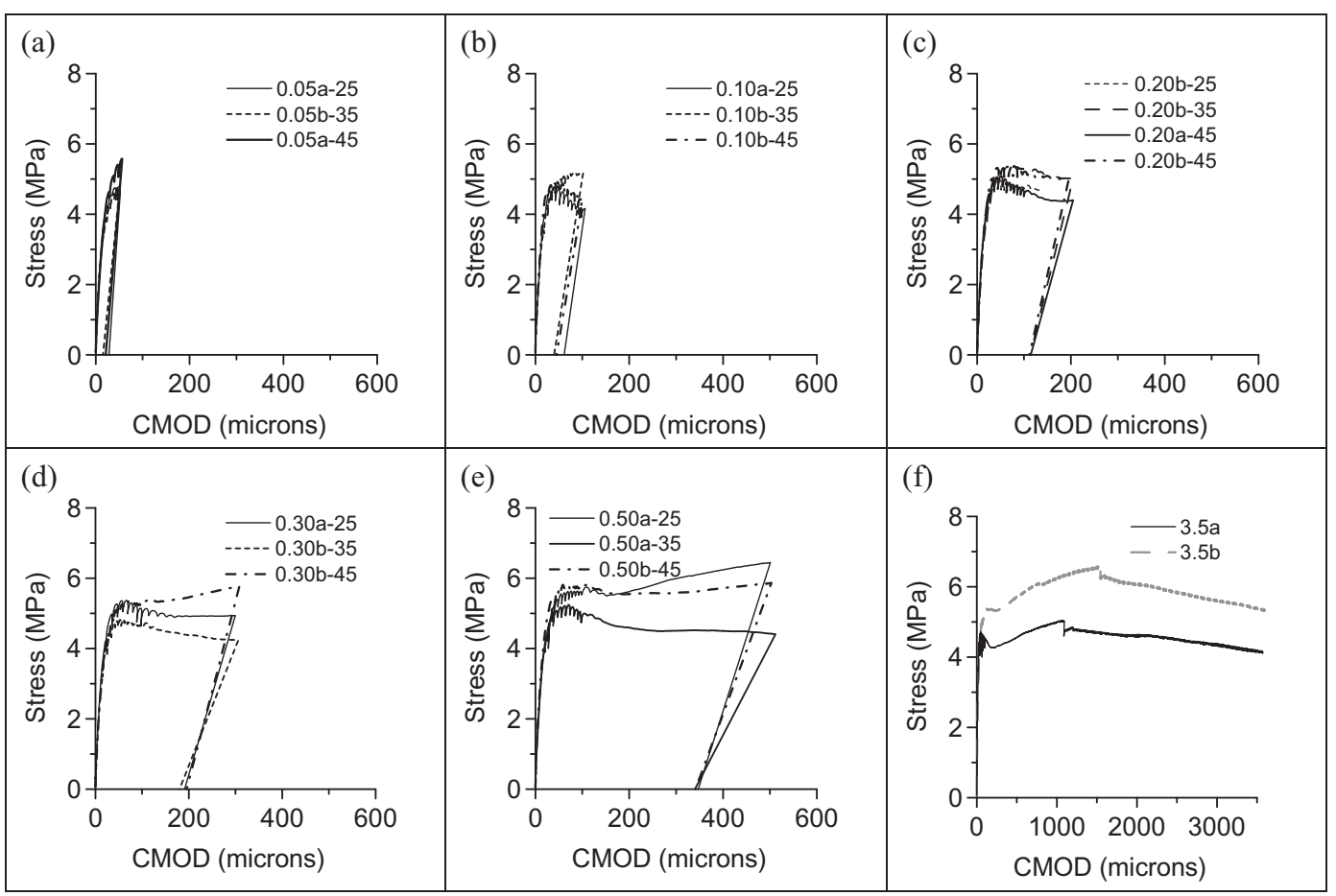

Fig. 3. Three point bending test curves up to different CMOD: (a) $0.05 \mathrm{~mm}$, (b) $0.1 \mathrm{~mm}$, (c) $0.2 \mathrm{~mm}$, (d) $0.3 \mathrm{~mm}$, (e) $0.5 \mathrm{~mm}$, (f) $3.5 \mathrm{~mm}$.

Table 2

Characterization and pre-cracking flexural test results.

\begin{tabular}{|c|c|c|c|c|c|c|c|c|c|}
\hline \multirow[t]{3}{*}{ Specimen } & \multirow[t]{3}{*}{$f_{\mathrm{L}}(\mathrm{MPa})$} & \multicolumn{4}{|c|}{$f_{\mathrm{R}, \mathrm{p}}(\mathrm{MPa})$} & $f_{\mathrm{R}, 1}(\mathrm{MPa})$ & $f_{\mathrm{R}, 3}(\mathrm{MPa})$ & \multirow[t]{3}{*}{$\mathrm{CMOD}_{\mathrm{p}}(\mu \mathrm{m})$} & \multirow[t]{3}{*}{$\mathrm{CMOD}_{\mathrm{pr}}(\mu \mathrm{m})$} \\
\hline & & \multicolumn{6}{|c|}{ CMOD $(\mathrm{mm})$} & & \\
\hline & & 0.05 & 0.1 & 0.2 & 0.3 & 0.5 & 2.5 & & \\
\hline $0.05 a-25$ & 4.24 & 4.78 & - & - & - & - & - & 52 & 28 \\
\hline $0.05 b-35$ & 3.90 & 4.79 & - & - & - & - & - & 51 & 15 \\
\hline $0.05 a-45$ & 3.58 & 5.31 & - & - & - & - & - & 56 & 21 \\
\hline $0.1 a-25$ & 4.00 & 4.70 & 4.06 & - & - & - & - & 106 & 61 \\
\hline $0.1 b-35$ & 3.54 & 4.80 & 5.15 & - & - & - & - & 102 & 40 \\
\hline $0.1 b-45$ & 4.66 & 4.28 & 4.37 & - & & - & - & 100 & 45 \\
\hline $0.2 b-25$ & 3.96 & 4.94 & 4.73 & - & - & - & - & 137 & * \\
\hline $0.2 b-35$ & 3.88 & 5.19 & 5.27 & 5.02 & - & - & - & 205 & 113 \\
\hline $0.2 a-45$ & 3.72 & 5.09 & 4.54 & 4.39 & - & - & - & 205 & 114 \\
\hline $0.2 b-45$ & 4.16 & 5.32 & 5.20 & 4.97 & - & - & - & 195 & 112 \\
\hline $0.3 a-25$ & 4.20 & 5.19 & 4.95 & 4.92 & 4.94 & - & - & 300 & 191 \\
\hline $0.3 b-35$ & 3.25 & 4.73 & 4.63 & 4.38 & 4.25 & - & - & 306 & 180 \\
\hline $0.3 b-45$ & 4.27 & 5.23 & 5.24 & 5.46 & 5.75 & - & - & 308 & 195 \\
\hline $0.5 a-25$ & 3.99 & 5.38 & 5.58 & 5.62 & 5.99 & 6.44 & - & 501 & 347 \\
\hline $0.5 a-35$ & 4.41 & 5.08 & 4.93 & 4.59 & 4.51 & 4.42 & - & 512 & 340 \\
\hline $0.5 b-45$ & 5.35 & 5.68 & 5.68 & 5.55 & 5.58 & 5.85 & - & 503 & 341 \\
\hline $3.5 a$ & 3.74 & 4.14 & 4.47 & 4.27 & 4.34 & 4.56 & 4.53 & & \\
\hline $3.5 \mathrm{~b}$ & 3.60 & 4.79 & 5.23 & 5.34 & 5.35 & 5.70 & 5.86 & & \\
\hline Average & 4.03 & 4.97 & 4.94 & 4.96 & 5.09 & 5.39 & 5.20 & & \\
\hline $\operatorname{CoV}(\%)$ & 12 & 8 & 9 & 10 & 13 & 16 & 18 & & \\
\hline
\end{tabular}

* Not measured, test unexpectedly stopped.

Table 3

Location and relative position for each specimen in the creep frames.

\begin{tabular}{|c|c|c|c|c|c|c|}
\hline Frame $\mathrm{N}^{\circ}$ & 1 & 2 & 3 & 4 & 5 & 6 \\
\hline Position Top & $0.05 a-25$ & $0.30 \mathrm{~b}-35$ & $0.20 \mathrm{~b}-25$ & $0.05 b-35$ & $0.05 a-45$ & $0.30 \mathrm{~b}-45$ \\
\hline Middle & - & - & $0.30 a-25$ & $0.50 a-35$ & $0.10 b-45$ & $0.50 \mathrm{~b}-45$ \\
\hline Bottom & $0.10 \mathrm{a}-25$ & $0.20 \mathrm{~b}-35$ & $0.50 a-25$ & $0.10 b-35$ & $0.20 b-45$ & $0.20 a-45$ \\
\hline$I_{\mathrm{n}}\left(\%\right.$ of $\left.f_{\mathrm{R}, 1}\right)$ & 25 & 35 & 25 & 35 & 45 & 45 \\
\hline 4PBT load $(\mathrm{kN})$ & 6.3 & 8.9 & 6.3 & 8.9 & 11.3 & 10.6 \\
\hline
\end{tabular}


Table 4

CMOD $(\mu m)$ evolution through time (creep period).

\begin{tabular}{|c|c|c|c|c|c|c|c|c|}
\hline \multirow[t]{2}{*}{ Specimen } & \multirow{2}{*}{$\begin{array}{l}f_{\mathrm{R}, \mathrm{c}} \\
(\mathrm{MPa})\end{array}$} & \multicolumn{6}{|c|}{ Under loading } & \multirow{2}{*}{$\begin{array}{l}\text { Unloading } \\
\text { CMOD }_{\text {cri }}\end{array}$} \\
\hline & & $\mathrm{CMOD}_{\mathrm{ci}}$ & $\mathrm{CMOD}_{\mathrm{ct}}^{14}$ & $\mathrm{CMOD}_{\mathrm{ct}}^{30}$ & $\mathrm{CMOD}_{\mathrm{ct}}^{60}$ & $\mathrm{CMOD}_{\mathrm{ct}}^{90}$ & $\mathrm{CMOD}_{\mathrm{ct}}^{180}$ & \\
\hline $0.05 a-25$ & 1.30 & 21 & 32 & 34 & 36 & 36 & 27 & 19 \\
\hline $0.05 b-35$ & 1.82 & 17 & 36 & 37 & 37 & 35 & 27 & 19 \\
\hline $0.05 a-45$ & 2.27 & 25 & 32 & 36 & 37 & 35 & 27 & 21 \\
\hline $0.1 \mathrm{a}-25$ & 1.35 & 31 & 46 & 46 & 49 & 49 & 46 & 26 \\
\hline $0.1 b-35$ & 1.89 & 22 & 32 & 39 & 38 & 36 & 32 & 19 \\
\hline $0.1 b-45$ & 2.34 & 25 & 52 & 57 & 65 & 69 & 69 & 29 \\
\hline $0.2 b-25$ & 1.31 & 35 & 50 & 58 & 59 & 64 & 60 & 35 \\
\hline $0.2 b-35$ & 1.88 & 30 & 54 & 54 & 56 & 57 & 57 & 26 \\
\hline $0.2 a-45$ & 2.34 & 49 & 72 & 82 & 87 & 92 & 91 & 45 \\
\hline $0.2 b-45$ & 2.54 & 65 & 100 & 110 & 120 & 130 & 132 & 64 \\
\hline $0.3 a-25$ & 1.35 & 32 & 43 & 49 & 50 & 52 & 50 & 29 \\
\hline $0.3 b-35$ & 1.82 & 98 & 121 & 135 & 143 & 153 & 161 & 74 \\
\hline $0.3 b-45$ & 2.34 & 51 & 70 & 76 & 80 & 80 & 78 & 48 \\
\hline $0.5 a-25$ & 1.38 & 32 & 75 & 78 & 75 & 74 & 69 & 25 \\
\hline $0.5 a-35$ & 1.95 & 90 & 123 & 135 & 148 & 149 & 154 & 85 \\
\hline $0.5 b-45$ & 2.46 & 71 & 97 & 107 & 118 & 125 & 125 & 70 \\
\hline
\end{tabular}

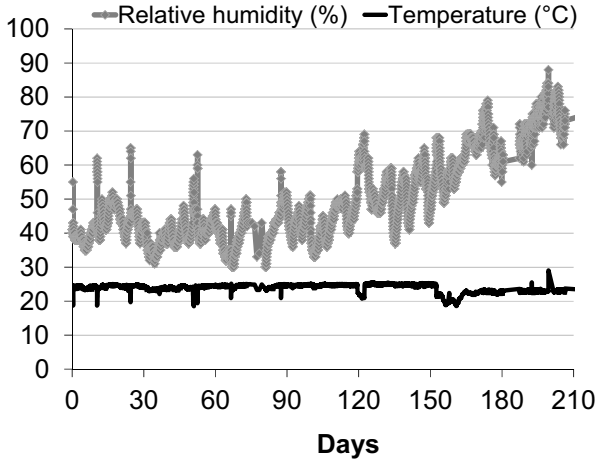

Fig. 4. Environmental conditions during the development of the creep period.

However, the second effect is not negligible in case of specimens working at a low stress level and with a small initial crack opening, as performed in this study.

To evaluate the shrinkage effect, additional series of unloaded prismatic specimens with the same concrete mix design were cast, instrumented and conserved in the same conditions than the loaded specimens. The drying shrinkage measurements for periods between 30 and 60 days, 60-90 days and 90-180 days were 47, 32 and 60 microstrains, respectively.

\subsection{CMOD evolution in time}

Table 4 summarizes the main results for the CMOD evolution under loading. The instantaneous $\left(\mathrm{CMOD}_{\mathrm{ci}}\right)$ and total measurements at different ages $\left(\mathrm{CMOD}_{\mathrm{ct}}{ }^{\mathrm{j}}\right)$ up to 180 days are given. In addition, the instantaneous CMOD recovered after unloading $\left(\mathrm{CMOD}_{\mathrm{cri}}\right)$ is presented. It must be noted that in many cases, mainly for very thin pre-cracks and for low sustained loads, a CMOD reduction was found at later ages, which can be explained considering the dial base length reductions due to concrete shrinkage as indicated in Section 3.3. When comparing $\mathrm{CMOD}_{\mathrm{ci}}$ (at loading) and $\mathrm{CMOD}_{\text {cri }}$ (at unloading), a good agreement can be observed; thus, it can be inferred that the application of long-term loads did not produce a major damage in the FRC internal structure.

Fig. 5 plots the CMOD deformation curves for all the specimens arranged by the initial damage level from 0.05 to $0.5 \mathrm{~mm}$, where the correction by the effect of the drying shrinkage explained in Section 3.3 is already updated. Each graph includes the specimens loaded at the same nominal stress level $\left(25,35\right.$ or $45 \%$ of $\left.f_{\mathrm{R}, 1}\right)$. The instantaneous $\mathrm{CMOD}_{\mathrm{ci}}$ due to loading stage, deferred $\mathrm{CMOD}_{\mathrm{cd}}{ }^{\mathrm{j}}$ during 180 days, together with the instantaneous recovery $\mathrm{CMOD}_{\mathrm{cri}}$ and the deferred recovery $\mathrm{CMOD}_{\text {crd }}$ during 30 days are shown in Fig. 5. It can be observed that for the specimens with lowest initial crack opening $(0.05 \mathrm{~mm})$ there is not a big influence of the stress levels on the deferred behavior. When increasing the initial damage level, the specimens develop more creep but with similar trend curves: the wider the initial crack, the higher the effect of the stress level on creep behavior (both in instantaneous and deferred CMOD). The scatter in $\mathrm{CMOD}_{\mathrm{ci}}$ values during loading is not negligible and may be caused by slight differences in initial stiffness and/ or in the number of fibers crossing the cracked section.

\subsection{Post-creep bending test}

Fig. 6 shows the complete stress-CMOD curves including the three stages of a complete flexural creep test: pre-cracking, creep period and post-creep bending test. Following similar criteria than in Fig. 5, each graph includes the specimens (having different $\mathrm{CMOD}_{\mathrm{p}}$ values) submitted to the same sustained load $(25,35$ and $45 \%$ of $f_{\mathrm{R}, 1}$ ) and additional plots are included showing the enlarged area corresponding to the first $600 \mu \mathrm{m}$. As a part of the post-creep stage, two loading-unloading cycles up to the same stress applied during the creep period were done. Each plot also includes the stress-CMOD curves of reference specimens 3.5a and 3.5b (aimed for FRC characterization) for comparison. It can be seen that there was not found significant loss in residual capacity by sustained loads. Moreover, it is possible that some improvements in residual capacity can be enhanced by the matrix strength evolution and the subsequent effects on fiber bond strength.

Once the post-creep bending stage tests were performed, the number of fibers was survey on the fracture surface. Table 5 arranges the residual stress $f_{\mathrm{R}, 3}$ as well as the fiber density $\left(\delta_{\mathrm{F}}\right)$. As expected, a clear relationship appears when comparing the individual results of residual strength $f_{\mathrm{R}, 3}$ and fiber density. Fig. 7 shows this relationship distinguishing the specimens exposed to sustained loads and the two specimens used for FRC characterization. Even for a same fiber density, the specimens that remained under sustained loads show higher residual capacity.

As already exposed, the load applied in the creep period was determined based on the nominal creep index $I_{\mathrm{n}}$ referred to the average $f_{\mathrm{R}, 1}$, which was obtained from the characterization tests and the specimens pre-cracked up to $0.5 \mathrm{~mm}$. Due to the relative 

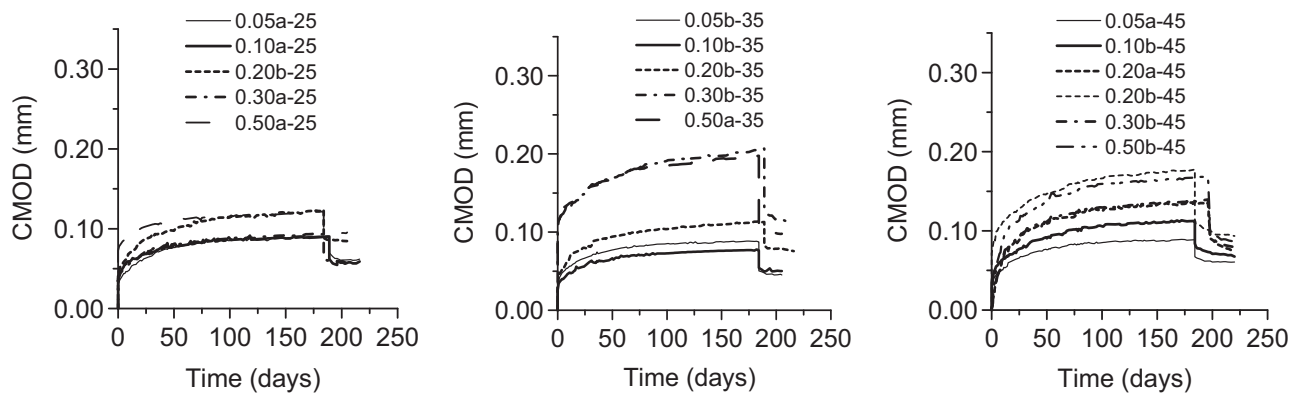

Fig. 5. CMOD evolution during the creep period.

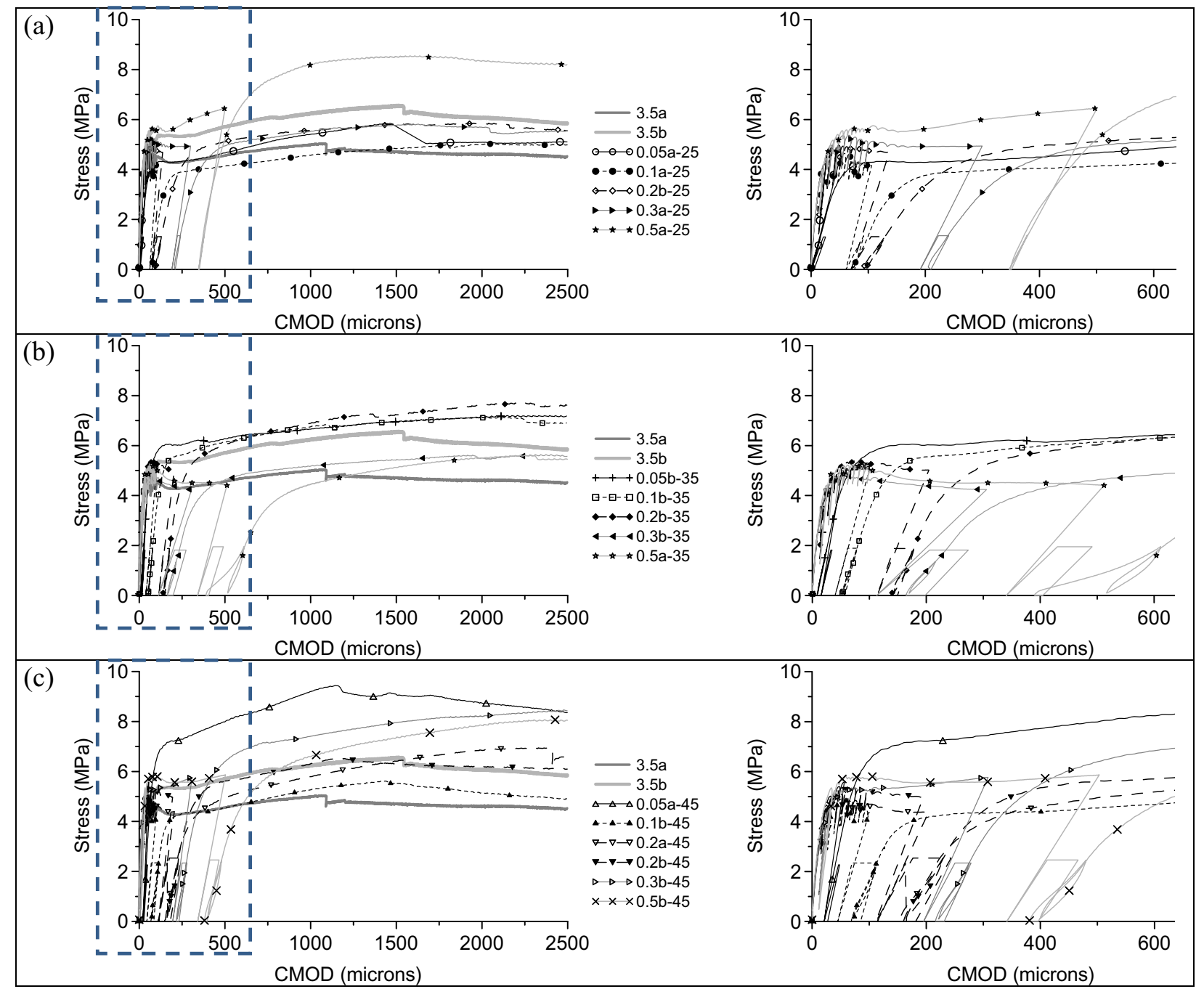

Fig. 6. Stress-CMOD curves including pre-cracking, creep period and post-creep stages at different stress levels $I_{n}$ : (a) $25 \%$, (b) $35 \%$ and (c) $45 \%$.

position in the frames, the load varies for each specimen depending on their position. Thus, the actual creep index $I_{\mathrm{c}}$ for each specimen is defined as the ratio $f_{R, c} l f_{R, 1}$. In addition, considering that there is a strong reliance between residual FRC strength and fiber content, the fiber density parameter was used to normalize the applied stress level $\left(I_{\mathrm{c}}\right)$ during the creep period of each specimen, into an effective stress level (or effective creep index, $I_{\text {ce }}$ ) obtained by multiplying the actual creep index $I_{\mathrm{c}}$ by the ratio between the average fiber density for all specimens (0.50) and the individual fiber density in each specimen. Table 5 details the $f_{\mathrm{R}, \mathrm{c}}$ of each specimen, in absolute and relative to $f_{R, 1}$ terms, and the resulting effective values for the applied load stress level during the creep period.

\section{Discussion}

Table 6 presents the Crack Opening Rate (COR) calculated for different time periods: 30-60 days ( $\left.\mathrm{COR}^{30-60}\right), \quad 60-90$ days $\left(\mathrm{COR}^{60-90}\right)$ and $90-180$ days $\left(\mathrm{COR}^{90-180}\right)$. The effective stress level of each specimen, as defined in the previous section, is also included as reference. Fig. 8 shows the individual and average values of COR for the different periods for each nominal stress level considered. As expected, the COR has a clear tendency to be reduced through the time. The scatter of the COR values for the first months is attributed to differences in both stress levels and initial crack openings, as concluded in previous researches $[2,20]$. 
Table 5

Post-creep bending test results and effective stress level obtained.

\begin{tabular}{|c|c|c|c|c|c|c|}
\hline \multirow[t]{2}{*}{ Specimen } & \multicolumn{2}{|c|}{ Post-creep test results } & \multicolumn{4}{|c|}{ Creep period stress level } \\
\hline & $\begin{array}{l}f_{\mathrm{R}, 3} \\
(\mathrm{MPa})\end{array}$ & $\begin{array}{l}\delta_{\mathrm{F}} \\
\left(\text { fibers } / \mathrm{cm}^{2}\right)\end{array}$ & $\begin{array}{l}f_{\mathrm{R}, \mathrm{c}} \\
(\mathrm{MPa})\end{array}$ & $\begin{array}{l}I_{\mathrm{n}} \\
(\%)\end{array}$ & $\begin{array}{l}I_{\mathrm{c}} \\
(\%)\end{array}$ & $\begin{array}{l}I_{\mathrm{ce}} \\
(\%)\end{array}$ \\
\hline $0.05 a-25$ & 5.11 & 0.45 & 1.30 & 25 & 24.1 & 26.8 \\
\hline $0.05 b-35$ & 6.05 & 0.45 & 1.82 & 35 & 33.7 & 37.5 \\
\hline $0.05 a-45$ & 8.37 & 0.60 & 2.27 & 45 & 42.1 & 35.1 \\
\hline $0.1 \mathrm{a}-25$ & 4.98 & 0.47 & 1.35 & 25 & 25.0 & 26.7 \\
\hline $0.1 b-35$ & 7.10 & 0.50 & 1.89 & 35 & 35.0 & 35.1 \\
\hline $0.1 b-45$ & 4.89 & 0.38 & 2.34 & 45 & 43.4 & 57.1 \\
\hline $0.2 b-25$ & 5.53 & 0.45 & 1.31 & 25 & 24.3 & 27.0 \\
\hline $0.2 b-35$ & 7.59 & 0.49 & 1.88 & 35 & 34.9 & 35.6 \\
\hline $0.2 a-45$ & 6.62 & 0.55 & 2.34 & 45 & 43.4 & 39.5 \\
\hline $0.2 b-45$ & 6.11 & 0.41 & 2.54 & 45 & 47.1 & 57.5 \\
\hline $0.3 a-25$ & 5.52 & 0.42 & 1.35 & 25 & 25.0 & 29.8 \\
\hline $0.3 b-35$ & 4.46 & 0.42 & 1.82 & 35 & 33.7 & 40.2 \\
\hline $0.3 b-45$ & 8.46 & 0.59 & 2.34 & 45 & 43.4 & 36.8 \\
\hline $0.5 a-25$ & 8.22 & 0.66 & 1.38 & 25 & 25.6 & 19.4 \\
\hline $0.5 a-35$ & 5.44 & 0.52 & 1.95 & 35 & 36.2 & 34.8 \\
\hline $0.5 b-45$ & 8.05 & 0.66 & 2.46 & 45 & 45.6 & 34.6 \\
\hline
\end{tabular}

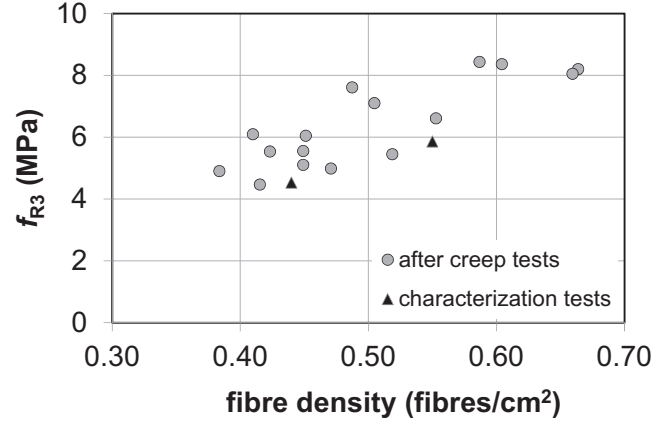

Fig. 7. Residual stress $f_{\mathrm{R}, 3}$ vs. fiber density $\delta_{\mathrm{F}}$ at the fracture surface.

The stress level and initial damage level have a significant influence on the early age creep behavior. After the first months under sustained load, the scatter is reduced and there is an important decrease in COR. However, clear velocity stabilization is not usually observed until 90 or 150 days, as observed in Fig. 8 from the average COR values.

This general trend can be also observed in Fig. 9, which represents the COR values based on the effective stress level $I_{c e}$ showing

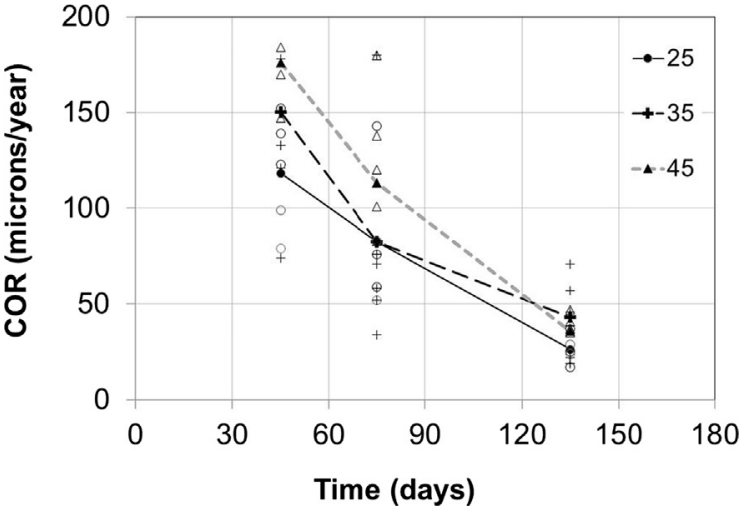

Fig. 8. Crack Opening Rate (COR) evolution through time.

clear tendencies: for the whole of values for a same time period, the higher the effective stresses, the higher the COR values.

Fig. 10 shows the COR values at different time periods vs. the total CMOD after $\mathrm{j}$ days - referred to origin of deformations $\left(\mathrm{CMOD}_{\mathrm{o}}^{\mathrm{j}}\right)-$ at the beginning of each time period $j\left(\mathrm{CMOD}_{\mathrm{pr}}+\right.$ $\left.\mathrm{CMOD}_{\mathrm{ci}}+\mathrm{CMOD}_{\mathrm{cd}}^{\mathrm{j}}\right)$, being $j$ the first day $(30,60$ or 90$)$ of the

Table 6

Crack Opening Rate (COR).

\begin{tabular}{|c|c|c|c|c|}
\hline \multirow[t]{2}{*}{ Specimen } & \multirow[t]{2}{*}{$I_{\mathrm{ce}}(\%)$} & \multicolumn{3}{|c|}{ COR ( $\mu \mathrm{m} /$ year $)$} \\
\hline & & 30-60 days & $60-90$ days & $90-180$ days \\
\hline $0.05 a-25$ & 26.8 & 152 & 76 & 17 \\
\hline $0.05 b-35$ & 37.5 & 121 & 52 & 19 \\
\hline $0.05 a-45$ & 35.1 & 133 & 58 & 19 \\
\hline $0.1 a-25$ & 26.7 & 123 & 59 & 25 \\
\hline $0.1 b-35$ & 35.1 & 74 & 34 & 22 \\
\hline $0.1 b-45$ & 57.1 & 184 & 101 & 37 \\
\hline $0.2 b-25$ & 27.0 & 139 & 143 & 37 \\
\hline $0.2 b-35$ & 35.6 & 133 & 76 & 46 \\
\hline $0.2 a-45$ & 39.5 & 147 & 120 & 35 \\
\hline $0.2 b-45$ & 57.5 & 202 & 180 & 47 \\
\hline $0.3 a-25$ & 29.8 & 99 & 83 & 29 \\
\hline $0.3 b-35$ & 40.2 & 178 & 180 & 71 \\
\hline $0.3 b-45$ & 36.8 & 170 & 83 & 41 \\
\hline $0.5 a-25$ & 19.4 & 79 & 52 & 24 \\
\hline $0.5 a-35$ & 34.8 & 245 & 71 & 57 \\
\hline $0.5 b-45$ & 34.6 & 220 & 138 & 37 \\
\hline
\end{tabular}


corresponding time period considered. The analyzed time lapses were 30-60, 60-90 and 90-180 days, avoiding the first ages in order to better focus the study in the tendency to creep stabilization. As observed for all time lapses considered, the COR values tend to increase as total $\mathrm{CMOD}_{\mathrm{o}}$ increases.

As the study shows that the stress level, the time under loading, and the initial crack width affected COR results, an equation for prediction purposes is proposed as a first approach:

$\mathrm{COR}_{\mathrm{th}}=I_{\mathrm{ce}} \cdot \mathrm{CMOD}_{\mathrm{o}}^{\mathrm{j}} \cdot \mathrm{k}_{\mathrm{p}}$

where $\mathrm{COR}_{\mathrm{th}}$ is the theoretical Crack Opening Rate (in $\mu \mathrm{m} / \mathrm{year}$ ), $I_{\mathrm{ce}}$ is the effective creep index (applied stress in \% of $f_{R, 1}$, normalized by fiber density), $\mathrm{CMOD}_{\mathrm{o}}^{\mathrm{j}}$ is the total crack opening at the beginning of the analyzed period (in $\mu \mathrm{m}$ ) and $\mathrm{k}_{\mathrm{p}}$ is a parameter that depends on the time period considered.

The $k_{p}$ values, obtained from an approach based on the Least Squares between theoretical and experimental COR, were 1.65, 1.03 and 0.39 for the periods 30-60 days, 60-90 days and 90180 days, respectively. For these periods, and for the different nominal stress levels considered, Fig. 11 depicts the curves of estimated COR for some total crack opening values. In all cases, for a same time period, COR values tend to increase as nominal stress level increases. Regarding the prediction of the measured COR values, Fig. 12 plots the comparison between estimated COR and

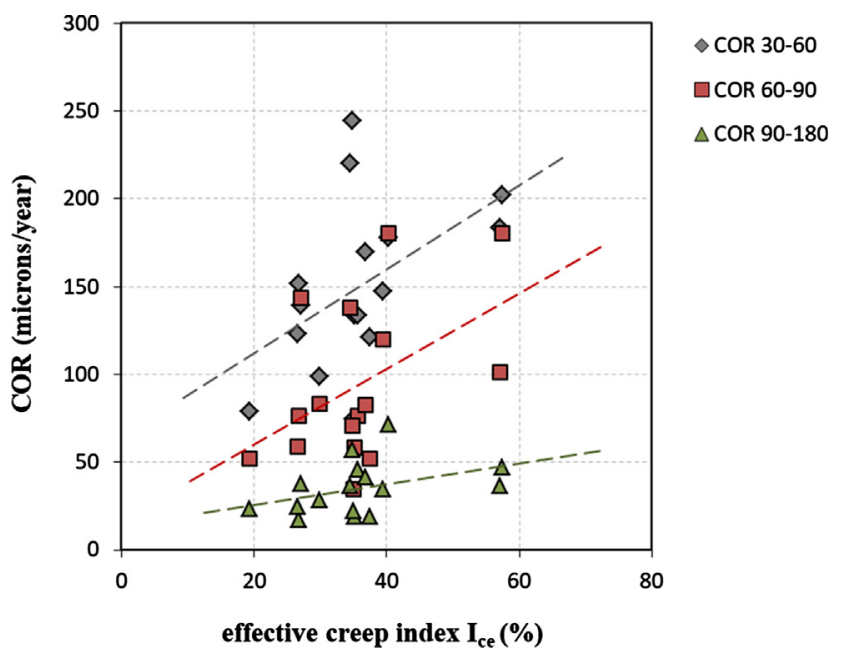

Fig. 9. Crack Opening Rate (COR) vs. effective creep index $I_{c e}$.



Fig. 10. COR vs. CMOD ${ }_{\mathrm{o}}^{\mathrm{j}}$ at the beginning of the analyzed time period.

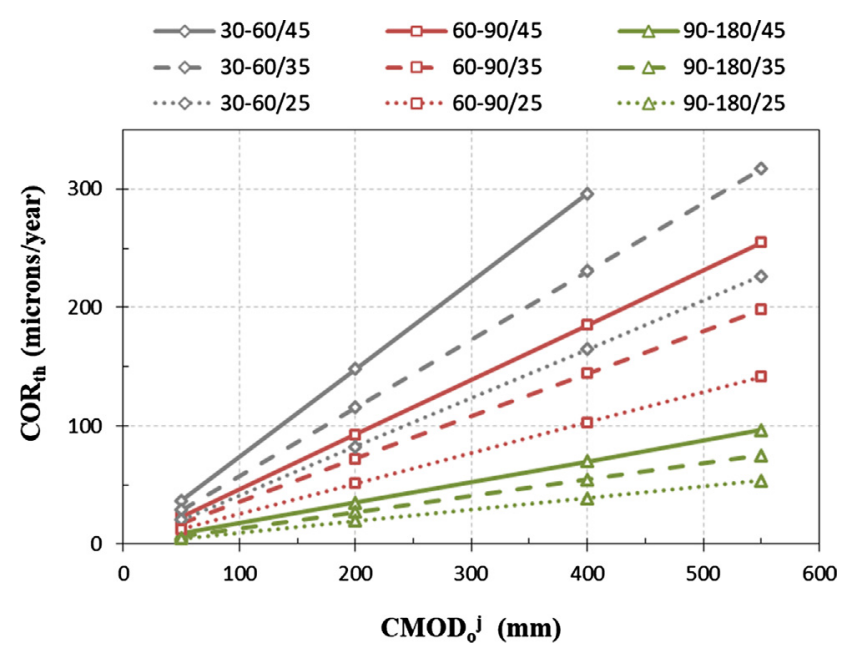

Fig. 11. $\mathrm{COR}_{\mathrm{th}}$ vs. $\mathrm{CMOD}_{\mathrm{o}}^{\mathrm{j}}$, for each analyzed time period and nominal stress level considered.

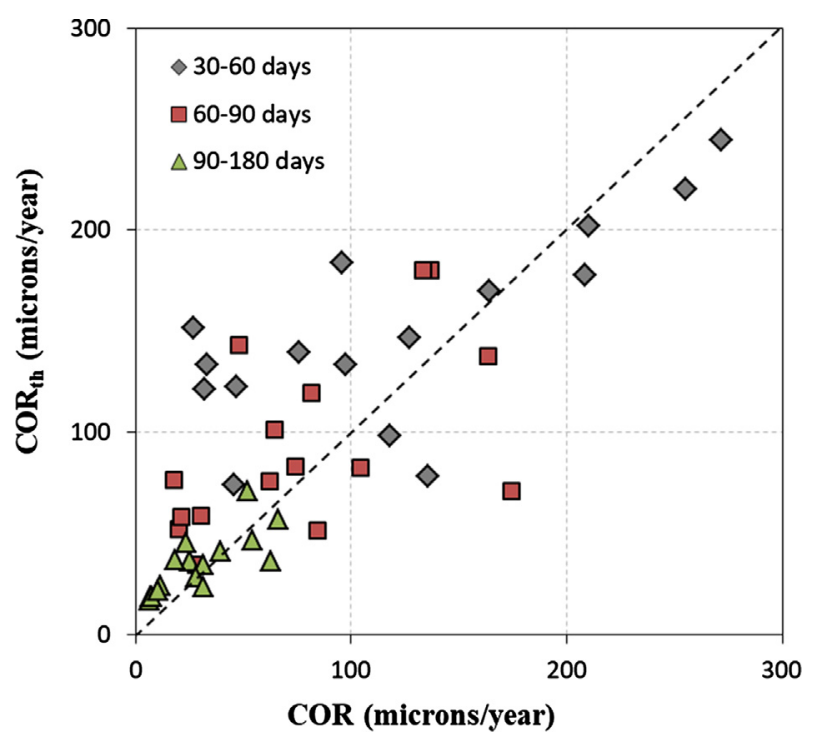

Fig. 12. Comparison between estimated COR and experimental COR results.

experimental COR results, differentiating each analyzed time period. As it can be observed, the adjustment of the prediction improves for high COR values and for the last/long time period.

The experimental results show that the previous damage of the concrete at a certain moment (regardless of the load history that caused it) with the applied load levels are two main factors influencing the creep behavior of cracked FRC. The proposed approach is quite simple as it assumes a linear dependence on both the initial CMOD and the applied stress. More complex approaches could be proposed even if the variability is relatively high. For the COR at long term (90-180 days) and at high COR values, the variability is reduced. Therefore, this approach is useful to evaluate the studied phenomenon and to predict experimental results in a sufficiently acceptable manner according to the actual state of knowledge.

\section{Conclusions}

With the aim of analyzing acceptable conditions for structures in service, the creep behavior of cracked steel FRC specimens by applying different stress levels and initial crack openings 
significantly lower than those traditionally used in the literature was studied. The main conclusions from this study are as follows:

- The creep results obtained for initial cracks lower than $0.5 \mathrm{~mm}$ and stress levels lower than $45 \%$ of $f_{\mathrm{R}, 1}$ indicate that the crack openings tend to stabilize and then long service life can be expected.

- The crack opening rate (COR) appears as a good tool to characterize the creep behavior of cracked steel FRC. The COR values drastically decrease after the first months under loading, though it is recommended the use of this parameter for times under loading exceeding 3 months.

- In a similar way than the significant dependency between fiber density and residual FRC strength, it has been verified that the fiber density strongly affect the creep results and contributes to increase their variability.

- It has been confirmed that for the studied stress levels, no matter the initial crack width, creep phenomenon does not generate negative effects on the residual capacity of FRC.

- The creep behavior is mainly affected by the stress level and also by the previous damage in the concrete. An expression to evaluate this influence is proposed.

Furthermore, under the load levels applied and for the initial openings of selected cracks, the deferred deformations in the cracked FRC were really low, and make possible to infer a great stability for years. However, as this study has been carried out on a steel FRC (Class 5c according to fib MC2010 [23]), it should be explored the response of FRC with other type of fibers materials or shape and also FRCs with softening post-peak behavior.

\section{Conflict of interest}

None.

\section{Acknowledgements}

Funding from projects CONICET PIP 112-201101-00765 “Development and characterization of fiber reinforced concretes for structural applications", UNLP PPID2012 "Damage processes in fiber reinforced concretes", UNLP 11/I188 "Fibre reinforced concretes and their contribution to the sustainable development", all three from Argentine, and BIA2016-78460-C3-1-R "Bases para el diseño de estructuras sostenibles de hormigón de muy alto rendimiento a nivel prenormativo / Diseño eficiente de estructuras de HMAR", from Spain, as well as the collaboration of Cementos Avellaneda and Maccaferri are greatly appreciated. The authors specially thank the collaboration of P. Bossio, A. Gerez, J. Anile and T. Gaitán in the support of experimental works.

\section{References}

[1] G. Zhao, M. Di Prisco, L. Vandewalle, Experimental investigation on uniaxial tensile creep behavior of cracked steel fiber reinforced concrete, Mater. Struct. 48 (2015) 3173-3185.
[2] R.L. Zerbino, B.E. Barragán, Long-term behavior of cracked steel fiberreinforced concrete beams under sustained loading, ACI Mat. J. 109 (2) (2012) 215-224

[3] N. Buratti, C. Mazzotti, M. Savoia, Post-cracking behaviour of steel and macrosynthetic fibre-reinforced concretes, Constr. Build. Mat. 25 (2011) 2713-2722.

[4] E.S. Bernard, Influence of fiber type on creep deformation of cracked fiberreinforced shotcrete panels, ACI Mat. J. 107 (5) (2010) 474-480.

[5] E. Vasanelli, F. Micelli, M.A. Aiello, G. Plizzari, Long term behavior of FRC flexural beams under sustained load, Eng. Struct. 56 (2013) 1858-1867.

[6] E. Vasanelli, F. Micelli, M.A. Aiello, G. Plizzari, Crack width prediction of FRC beams in short and long term bending condition, Mater. Struct. 47 (2014) 3954.

[7] W.P. Boshoff, V. Mechtcherine, G.P.A.G. van Zijl, Characterising the timedependant behaviour on the single fibre level of SHCC: Part 1: mechanism of fibre pull-out creep, Cem. Concr. Res. 39 (2009) 779-786.

[8] P.D. Nieuwoudt, W.P. Boshoff, Time-dependent pull-out behaviour of hookedend steel fibres in concrete, Cem. Concr. Comp. 79 (2017) 133-147.

[9] M. Di Prisco, G. Plizzari, L. Vandewalle, Fiber reinforced concrete: new design perspectives, Mater. Struct. 42 (9) (2009) 1261-1281.

[10] J.C. Walraven, High performance fiber reinforced concrete: progress in knowledge and design codes, Mater. Struct. 42 (2009) 1247-1260.

[11] S.E. Arango, P. Serna, J.R. Martí-Vargas, E. García-Taengua, A test method to characterize flexural creep behaviour of pre-cracked FRC Specimens, Exp. Mech. 52 (8) (2012) 1067-1078.

[12] N. Buratti, C. Mazzotti, Experimental tests on the effect of temperature on the long-term behaviour of macrosynthetic Fibre Reinforced Concretes, Constr. Build. Mat. 95 (2015) 133-142.

[13] ASTM C1399, Standard test method for obtaining average residual-strength of fiber-reinforced concrete, American Society for Testing and Materials, West Conshohocken, PA, 2015.

[14] T.C. Rilem, 162-TDF, Test and design methods for steel fiber-reinforced concrete, $\sigma-\varepsilon$ design method, Mater. Struct. 36 (262) (2003) 560-567.

[15] European Committee for Standardization, European Standard EN 14651:2007: Test method for metallic fibered concrete - Measuring the flexural tensile strength (limit of proportionality (LOP), residual), Brussels, 2007.

[16] E. García-Taengua, S. Arango, J.R. Martí-Vargas, P. Serna, Flexural creep of stee fiber reinforced concrete in the cracked state, Constr. Build. Mat. 65 (2014) 321-329.

[17] A. Abrishambaf, J.A.O. Barros, V.M.C.F. Cunha, Time-dependent flexural behaviour of cracked steel fibre reinforced self-compacting concrete panels, Cem. Concr. Res. 72 (2015) 21-36.

[18] P. Serna Ros, J.R. Martí-Vargas, M.E. Bossio, R. Zerbino, Creep and residual properties of cracked macro-synthetic fibre reinforced concretes, Mag. Concr. Res. 68 (4) (2016) 197-207.

[19] R. Zerbino, D.H. Monetti, G. Giaccio, Creep behaviour of cracked steel and macro-synthetic fibre reinforced concrete, Mater. Struct. 49 (2016) $3397-$ 3410.

[20] A. Llano-Torre, P. Serna, R. Zerbino, J.R. Martí-Vargas, Effect of initial crack opening on flexural creep behavior of FRC specimens, RILEM Proceedings PRO 116-9th RILEM International Symposium on Fiber Reinforced Concrete: the Modern Landscape (BEFIB 2016), Vancouver, 2016, pp. 117-126.

[21] U. Gossla, K.A. Rieder, Zeitabhängiges Verhalten von Makrokunststofffaserbeton und dessen Einfluss auf die Bemessung von Industriefußböden, Beton und Stahlbetonbau 104 (2009) 76-87.

[22] P.D. Nieuwoudt, A.J. Babafemi, W.P. Boshoff, The response of cracked steel fibre reinforced concrete under various sustained stress levels on both the macro and single fibre level, Constr. Build. Mat. 156 (2017) 828-843.

[23] Fédération Internationale du Béton, fib Model Code for Concrete Structures 2010, Ernst \& Sohn, Berlin, 2013, pp. 74-150.

[24] A. Llano-Torre, P. Serna, S.H.P. Cavalaro, International Round Robin Test on creep behavior of FRC supported by the RILEM TC 261-CCF, RILEM Proceedings PRO 116-9th RILEM International Symposium on Fiber Reinforced Concrete: The Modern Landscape (BEFIB 2016), Vancouver, 2016, pp. 127-140.

[25] A. Llano-Torre, S.E. Arango, E. García-Taengua, J.R. Martí-Vargas, P. Serna, Influence of Fibre Reinforcement on the Long-Term Behaviour of Cracked Concrete, in: P. Serna, A. Llano-Torre, S. Cavalaro (Eds.), Creep Behaviour in Cracked Sections of Fibre Reinforced Concrete. RILEM Bookseries, Springer, Dordrecht, 2017. 